\title{
Barriers and Enablers That Influence Utilization of Ultrasound Screening Services among Antenatal Women in Kajiado and Kisii Counties Kenya
}

\author{
Micah Matiang' ${ }^{1}{ }^{*}$, Koen Joosse ${ }^{2}$, Priscillah Ngunju ${ }^{1}$, Colleta Kiilu1 ${ }^{1}$, Romy Harkx ${ }^{3}$, \\ Marianne Hangelbroek ${ }^{3}$, Jarim Omogi ${ }^{4}$ \\ ${ }^{1}$ Amref International University (AMIU), Nairobi, Kenya \\ ${ }^{2}$ Philips Foundation, Amsterdam, The Netherlands \\ ${ }^{3}$ Amref, The Netherlands \\ ${ }^{4}$ ITROMID-Jomo Kenyatta University of Agriculture and Technology, Juja, Kenya \\ Email: ^miconyiego@gmail.com, ${ }^{\star}$ micyiego@yahoo.com, ${ }^{\star}$ Micah.Matiangi@amref.ac.ke
}

How to cite this paper: Matiang'i, M., Joosse, K., Ngunju, P., Kiilu, C., Harkx, R., Hangelbroek, M. and Omogi, J. (2021) Barriers and Enablers That Influence Utilization of Ultrasound Screening Services among Antenatal Women in Kajiado and Kisii Counties Kenya. Open Journal of Clinical Diagnostics, 11, 1-17.

https://doi.org/10.4236/ojcd.2021.111001

Received: November 27, 2020

Accepted: February 2, 2021

Published: February 5, 2021

Copyright $\odot 2021$ by author(s) and Scientific Research Publishing Inc. This work is licensed under the Creative Commons Attribution International License (CC BY 4.0).

http://creativecommons.org/licenses/by/4.0/

\begin{abstract}
Background: The World Health Organization recommends to have all pregnant women to undergo an obstetric ultrasound scan before 24 weeks gestation. However, this has been a challenge as a result of limited access to appropriate Point of Care Ultrasound Screening (POCUS) services in lower levels of developing countries' Health Systems, cost of care, skills gap among care providers and unclear regulatory policy frameworks. Obstetric Ultrasound scan helps to confirm viability of a pregnancy, gestational age, multiple pregnancies and it also helps rule out fetal abnormalities early enough. Methods: One year after intervention, a cross-sectional study was carried in the two pilot counties of Kisii (rural) and Kajiado (peri-urban). This followed after selected midwives in the two counties were trained on basic obstetric ultrasound screening for ANC women. A total of 366 women who were either in their last phases of pregnancy or had delivered within three months before the survey were interviewed. Cumulatively, the 36 midwives had screened 1,250 mothers out of whom 18 high risk pregnancies were identified. Open Data Kit (ODK) was used to collect quantitative data and analysed using STATA version 15. Descriptive statistics were used to summarize the data test associations between variables. Bivariate and logistic regression was used to identify predictive variables, and ORs with $95 \%$ confidence intervals used to measure the strength of the associations. Findings: Slightly more than a third (36\%) of the women had recently delivered. In total, Kisii (rural county) had a representation of $59 \%$ of the respondents. Half of the respondents were aged between 25 - 34 years, $55 \%$ of the women interviewed were housewives
\end{abstract}


while $48 \%$ had secondary level of education. Only $21 \%$ of the women had undergone routine ultrasound screening before 24 weeks of gestation with the average distance travelled by majority (45\%) of the respondents to access the POCUS service being $3-5 \mathrm{~km}$. The need to confirm a pregnancy's gestation was the major (68.1\%) motivator for seeking the service in the two pilot counties. Employment status, household income, education level, pregnancy gestation and distance to the facility had a statistical significance $(P<0.05)$ with ultrasound utilization. Highest education level, pregnancy gestation and distance to the nearest ultrasound screening facility were found to significantly predict the likelihood of utilizing the ultrasound services $(P<0.05)$. The initial training and continuous hands-on coaching of midwives by TOTs contributed a lot to acquisition of the desired basic obstetric ultrasound screening skills. Conclusion: Women in developing countries are eager to access obstetric ultrasound screening services but for limited opportunities and sustainable implementation frameworks on Point of Care Ultrasound Screening (POCUS) services. Training and continuous coaching of frontline health professionals are critical in deployment of POCUS but there is limited access to standardised training content.

\section{Keywords}

Point of Care Ultrasonography Screening (POCUS), Midwives, Antenatal, Primary Health Care Settings, Business Model

\section{Introduction}

According to the International Federation of Gynaecology and Obstetrics (FIGO) report [1], obstetric ultrasound is an integral part of prenatal care for pregnant women. Unequal distribution and high cost of obstetric ultrasound technology in low resource settings have continued to affect access and utilisation of early pregnancy obstetric ultrasonography services. Further to this, the World Health Organization (WHO) [2] concurs that, a midwife with a full-scope of midwifery skills, is able to meet $87 \%$ of the needs of pregnant women and newborns. However, the developing countries' health system [3] is one with staffing shortages aggravated by limited financial muscle for governments to hire additional staff; in Kenya only $30 \%$ of the 3000 plus nurse midwives that graduate annually get formerly secure employment.

Women in Sub-Saharan Africa are yet to embrace early pregnancy ultrasound screening due to factors that vary from individual challenges in health seeking behaviours to health facilities capacity limitations and unclear national policies environment [4]. While WHO recommends at least one Obstetric Ultrasound for pregnant women [5], FIGO recommends two ultrasound screens for all pregnant women during the first and second trimesters to mitigate risks associated with adverse perinatal outcomes.

In Kenya, only $62 \%$ of pregnant women have access to skilled care and comparatively, $50 \%$ of pregnant women in rural areas receive skilled care compared 
to $82 \%$ of their counterparts in the urban area [6]. Among the factors contributing to limited quality of ANC care is lack of adequate diagnostic services, cost of care in primary health care settings and shortage of qualified professional human resource for health in underserved settings.

In addition to lack of standardised obstetric ultrasound training guidelines for frontline health workers in Sub-Saharan Africa (SSA) countries, lower knowledge among pregnant women on usefulness of obstetric ultrasound [7] has contributed to poor uptake of the service. Mixed cultural and societal perceptions in developing countries as well as lack of appropriate communication between caregivers and pregnant women on sonography services [8] have also been presumed to influence uptake of the service. The limitations of appropriate technology and lack of skilled caregivers in obstetric sonography in developing countries' health care settings [9] are among the reasons affecting uptake of the service. Studies conducted in limited resource settings [10] reveal that cost of care alone has no influence on perinatal outcomes although it does affect utilisation of a health service. Limited technology and lack of expert staff in areas of radiography and ultrasonography in primary health care settings [11] have grossly affected the health devolved units (county governments) to implement the Managed Equipment Services (MES) in Kenya which is meant to take technology closer to the people.

\section{Intervention}

A pilot project got initiated in two pilot counties in Kenya to assess midwives' uptake of basic obstetric ultrasound screening skills and women's utilisation of Point of Care Ultrasound Screening Services (POCUS) in selected Primary Health Care (PHC) facilities in two pilot counties. The project team deployed Portable ultrasound technology in 10 selected points of care after 36 midwives got trained both physically and on-line (using standardised e-Learning content) on how to offer the service. Professional Radiographers were trained by Sonographers to play the role of TOTs for the selected midwives in the project which included coaching and mentoring them for a period of 3 months. To make the service sustainably available, mothers were required to pay USD 5 per screening session to meet operational costs for consumables, incentivise the service providers and regularly maintain the equipment. Over 1,000 mothers were screened within 12 months in the two pilot counties with 10 Point of Care Ultrasound Screening (POCUS) facilities.

\section{Method}

\subsection{Study Location and Design}

A descriptive cross-sectional study was undertaken among midwives in Kisii and Kajiado Counties in Kenya. According to the Kenya National Bureau of Statistics (KNBS) Kisii County has a population of 1,266,860 while Kajiado has 1,157,873 (Kenya National Bureau of Statistics, 2019). The midwives in the two Counties 
are homogenous professionally given that they undergo the same training in government approved colleges.

A list of all primary health facilities was stratified by region (Kajiado and Kisii) and by type of facility (public and non-public). The facilities were then purposively selected to ensure representation of views both from the public and non-public primary health care facilities in the two counties. The mothers who were either in their last phases of pregnancy or had delivered within three months before the survey were randomly selected from the health facilities in pilot sites. The number of study participants recruited per county was proportionate to the number of women of reproductive age in each county and the number of mothers who had undergone obstetric ultrasound screening in each of the pilot sites for a period of one year.

\subsection{Data Collection}

A structured questionnaire converted into a mobile application tool open data kit (ODK) was used to elicit information from mothers who were either in their last phases of pregnancy or had delivered within three months before the survey. Six research assistants from each county who had the ability to use mobile phone applications, had a training in health or social sciences and were familiar with the respective regions had a two-day training for this study. The questionnaire and consent forms were pre-tested with 41 (10\%) respondents and revised based on feedback received.

\subsection{Data Management and Analysis}

\subsubsection{Questionnaire}

The questionnaire data already captured in ODK was later converted to excel. The data was later converted to STATA version 15 that was used to calculate descriptive statistics for study variables. Tables were used to graphically show the respective findings. Bivariate and logistic regression was used to identify predictive variables, and ORs with $95 \%$ confidence intervals used to measure the strength of the associations. The study adopted a two-sample approach: the difference between two populations (Kisii and Kajiado) with specified anticipated precision being $P_{1}(0.5)$ and $P_{2}(0.5)$ at a significance level of 0.005 .

\subsubsection{Ethics}

Authorization for data collection was obtained from the relevant administrative authorities in Kajiado and Kisii Counties in Kenya. Oral and written informed consent was the foundation for the participation of eligible midwives. The participants were informed that they could withdraw their participation at any time during the research process. To ensure confidentially, all the questionnaires were coded to prevent identification of any individual participant.

\subsubsection{Limitations and Delimitations}

The project took place in the period of the COVID-19 pandemic which also li- 
mited utilization of ANC services. People in primary health care settings sometimes face language barrier challenges but enumerators were selected on the basis of being able to speak local languages in addition to the two national languages. Enumerators and project midwives were provided with PPEs.

\section{Results}

\subsection{Social-Demographic Characteristics of the Respondents}

As shown in Table 1 total of 366 women were interviewed from the two pilot counties (representing $88.8 \%$ ) of the targeted sample size of 412 women. More than half (59\%) of the respondents were from Kisii (rural) county while the rest were from Kajiado (peri-urban) county in Kenya. More than a third (36\%) of the women interviewed in the pilot sites had recently delivered. Half of the respondents were aged between 25 - 34 years while $5.2 \%$ were aged below 18 years. Notably, $68 \%$ of the respondents had history of receiving skilled ANC services either recently or in the previous pregnancy. More than half of the respondents (55\%) were housewives, $34 \%$ were self-employed and $12 \%$ were employed. Less than half of the respondents had secondary level of education while $26 \%$ had primary level of education and $18 \%$ had mid-level college level of education as summarized in Table 1.

Table 1. Social-demographic characteristics of the respondents $(n=366)$.

\begin{tabular}{|c|c|c|}
\hline Variable & Frequency & Percentage (\%) \\
\hline \multicolumn{3}{|l|}{ County } \\
\hline Kisii & 215 & 59 \\
\hline Kajiado & 151 & 41 \\
\hline \multicolumn{3}{|l|}{ Education Level } \\
\hline None & 17 & 4.6 \\
\hline Primary & 95 & 26 \\
\hline Secondary & 176 & 48.1 \\
\hline Mid-level college & 65 & 17.8 \\
\hline University & 13 & 3.6 \\
\hline \multicolumn{3}{|l|}{ Income (\$) } \\
\hline$<100$ & 250 & 68.3 \\
\hline $100-300$ & 81 & 22.1 \\
\hline $301-500$ & 22 & 6 \\
\hline $501-700$ & 8 & 2.2 \\
\hline 700 & 5 & 1.4 \\
\hline \multicolumn{3}{|l|}{ Employment Status } \\
\hline Housewife & 201 & 54.9 \\
\hline Self employed & 123 & 33.6 \\
\hline Employed & 42 & 11.5 \\
\hline \multicolumn{3}{|l|}{ Marital Status } \\
\hline Married & 303 & 82.8 \\
\hline Separated & 6 & 1.6 \\
\hline Single & 55 & 15 \\
\hline Others & 2 & 0.5 \\
\hline
\end{tabular}




\subsection{Utilization of Ultrasound Screening Services by Women in Primary Health Care Settings}

Almost half (49.7\%) of the respondents had undergone obstetric ultrasound screening in their latest (current) pregnancy and only 22\% (81) had gone for routine obstetric ultrasound screening in their previous pregnancies. Out of the screened respondents, $36 \%$ were screened at a gestational age of $25-30$ weeks. On access to ultrasound screening services, majority of the respondents (45\%) travelled a distance of $3-5 \mathrm{~km}$ to access ultrasound screening within the two pilot counties, $17 \%$ travelled $6-10 \mathrm{~km}$ and $5 \%$ of them travelled for more than $10 \mathrm{~km}$ to access ultrasound screening services as shown in Table 2. Out of those done an obstetric ultrasound in their recent pregnancy, $71 \%$ of them accessed the service in a public health facility within pilot sites, $24 \%$ of them got the service in private health facilities and $5 \%$ in faith based (mission) hospitals.

As depicted in Table 3, reasons for utilizing ultrasound services varied across the counties with the main reason in Kisii (rural) county being to know the health status of the foetus while in Kajiado (peri-urban) county the main women's motivation was to confirm the pregnancy gestation. Overall, $81.3 \%$ went for the services to know the health status of the foetus.

Further analysis to understand the factors that influence seeking of ultrasound services in a facility revealed that customer care $(M=4.78)$, health education received $(M=4.75)$, level of privacy $(M=4.72)$, benefits of ultrasound screening $(\mathrm{M}=4.66)$ and waiting time $(\mathrm{M}=4.35)$ as the top five influencers in that order. Other factors included financial cost, the type of facility offering the services, distance to the facility, and sex of the health provider offering the service, previous ultrasound experience and the side effects associated with ultrasound as shown in Table 4.

Table 2. Utilization of ultrasound screening services by women in primary health care settings.

\begin{tabular}{lcc}
\hline \multicolumn{1}{c}{ Variable } & Frequency & Percentage \\
\hline $\begin{array}{l}\text { Undergone obstetric ultrasound screening } \\
\text { Yes }\end{array}$ & 182 & \\
No & 184 & 59.7 \\
Pregnancy gestation & & \\
$1^{\text {st }}$ Trimester & 32 & 8.7 \\
$2^{\text {nd }}$ Trimester & 107 & 29.2 \\
$3^{\text {rd }}$ Trimester & 96 & 26.2 \\
Already delivered & 131 & 35.8 \\
Distance to the nearest ultrasound screening facility & & \\
$<3 \mathrm{~km}$ & 120 & 32.8 \\
$3-5 \mathrm{~km}$ & 165 & 45.1 \\
6 - $10 \mathrm{~km}$ & 62 & 16.9 \\
$>10 \mathrm{~km}$ & 19 & 5.2 \\
\hline
\end{tabular}


Table 3. Reasons for utilizing ultrasound services.

\begin{tabular}{lccc}
\hline \multicolumn{1}{c}{ Characteristics } & $\begin{array}{c}\text { Kajiado-Per } \\
\text { urban county }\end{array}$ & $\begin{array}{c}\text { Kisii; rural } \\
\text { county }\end{array}$ & Total cases \\
\hline Know the fetal sex & $35(55.6)$ & $50(42.0)$ & $85(46.7)$ \\
Confirm the pregnancy gestation & $51(81.0)$ & $73(61.3)$ & $124(68.1)$ \\
Discover the fetal position & $48(76.2)$ & $72(60.5)$ & $120(65.9)$ \\
Diagnose pregnancy complications & $31(49.2)$ & $46(38.7)$ & $77(42.30)$ \\
Know health status of the foetus & $49(77.8)$ & $99(83.2)$ & $148(81.3)$ \\
Know expected date of delivery & $50(79.4)$ & $58(48.7)$ & $108(59.3)$ \\
Visualizing image of the baby & $21(33.3)$ & $24(20.2)$ & $45(24.7)$ \\
Correct fetal abnormalities & $3(4.8)$ & $8(6.7)$ & $11(6.0)$ \\
Other & $7(11.1)$ & $1(0.8)$ & $8(4.4)$ \\
\hline
\end{tabular}

Table 4. Factors that influence access to an ultrasound facility.

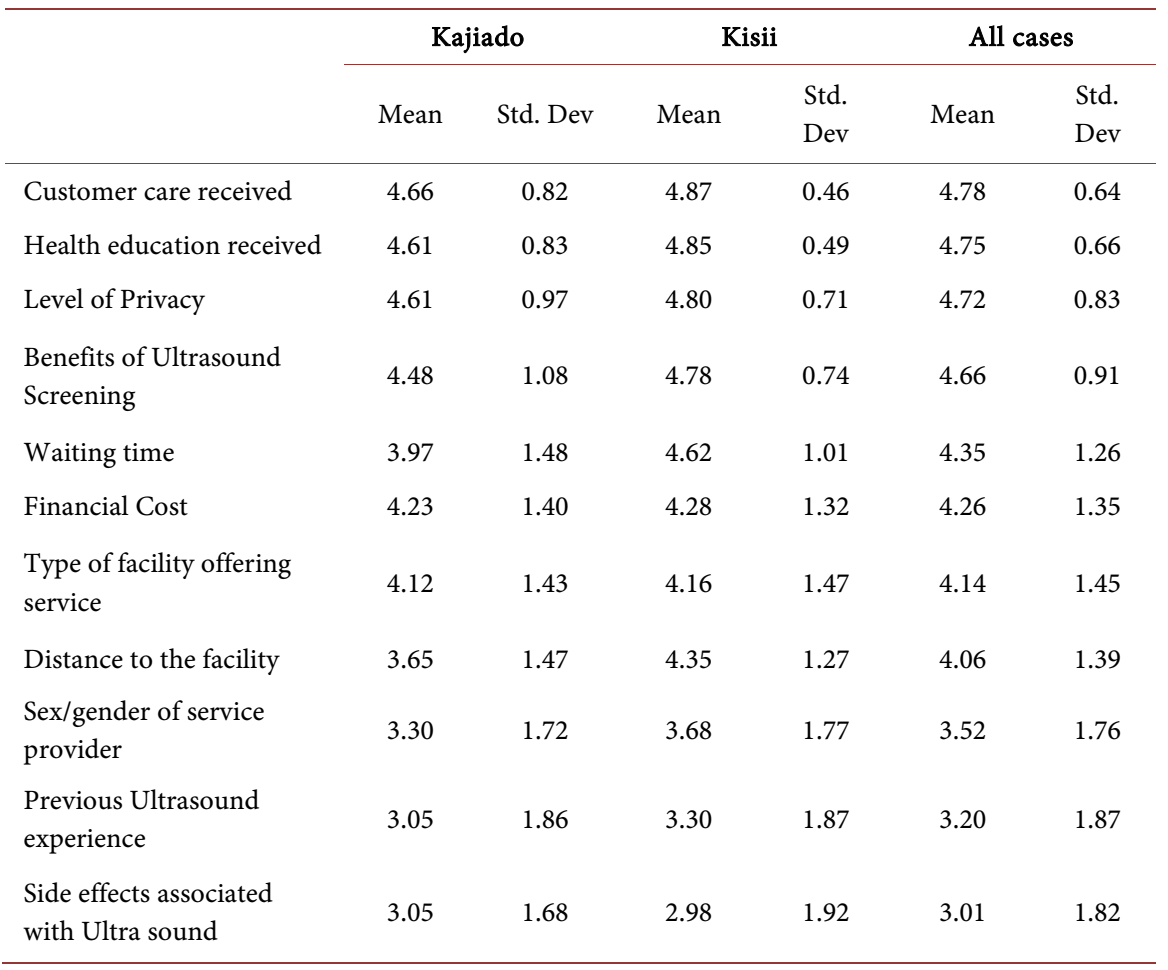

\subsection{Barriers to Accessing Ultrasound Screening}

Overall, Lack of money was identified by the respondents as the main barrier to accessing ultrasound screening. In Kajiado County, lack of ultrasound services, limited awareness, fear of ultrasound side-effects and cultural beliefs were the most critical barriers overall as shown in Figure 1.

\subsection{Relationship between Ultrasound Utilization and Other Factors}

As shown in Table 5, a statistically significant relationship between obstetric ultrasound utilization and employment status $\left(\chi^{2}=13.64, P=0.001, d f=2\right)$, 


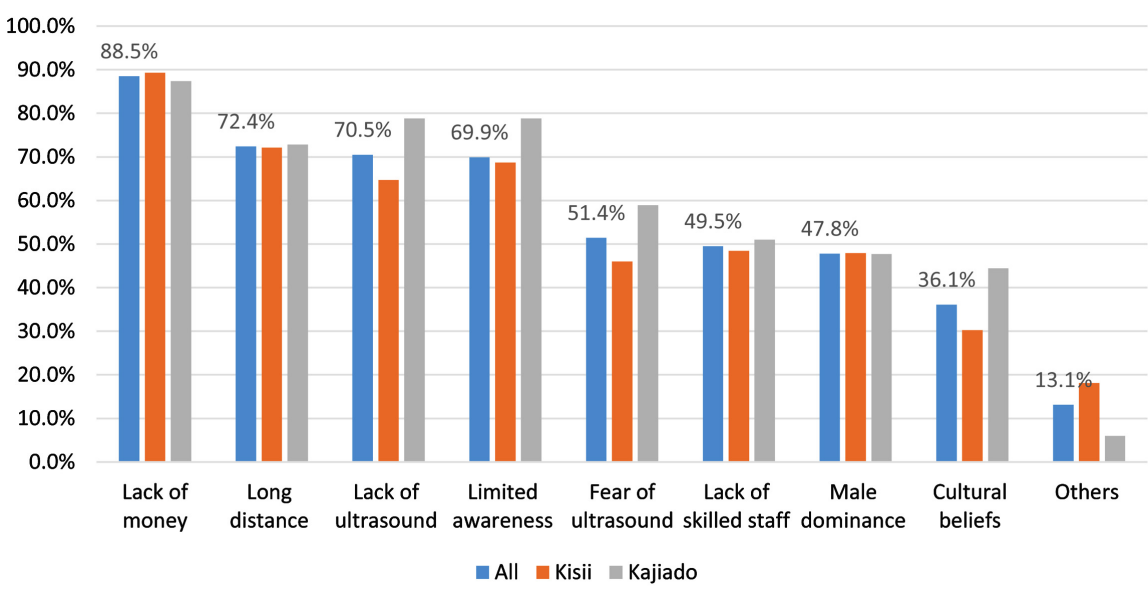

Figure 1. Barriers to accessing ultrasound services $n=366$.

Table 5. Comparative competencies rating by mid-wives (self-rating) and TOTs.

\begin{tabular}{|c|c|c|c|c|c|}
\hline \multicolumn{2}{|l|}{ Parameter rated } & \multirow{2}{*}{$\begin{array}{l}\mathrm{N} \\
19\end{array}$} & \multirow{2}{*}{$\begin{array}{r}\text { Mean } \\
4.52\end{array}$} & \multirow{2}{*}{$\begin{array}{c}\begin{array}{c}\text { Std. } \\
\text { Deviation }\end{array} \\
0.52\end{array}$} & \multirow{3}{*}{$\begin{array}{c}\text { P-value } \\
0.756\end{array}$} \\
\hline \multirow{2}{*}{ System Knowledge } & Self-rating & & & & \\
\hline & ToT & 19 & 4.55 & 0.50 & \\
\hline \multirow{2}{*}{ Scanning } & Self-rating & 19 & 4.60 & 0.49 & \multirow{2}{*}{0.834} \\
\hline & ToT & 19 & 4.47 & 0.64 & \\
\hline \multirow{2}{*}{ Operating Parameters } & Self-rating & 19 & 4.22 & 0.71 & \multirow{2}{*}{0.621} \\
\hline & ToT & 19 & 4.14 & 0.70 & \\
\hline \multirow{2}{*}{ Scanning as per Protocol } & Self-rating & 19 & 4.28 & 0.59 & \multirow{2}{*}{0.929} \\
\hline & ToT & 19 & 4.23 & 0.71 & \\
\hline \multirow{2}{*}{$\begin{array}{l}\text { Determining the appropriate } \\
\text { first trimester protocol }\end{array}$} & Self-rating & 19 & 3.68 & 0.95 & \multirow{2}{*}{0.520} \\
\hline & ToT & 19 & 3.89 & 0.76 & \\
\hline \multirow{2}{*}{$\begin{array}{l}\text { Performing the embryonic } \\
\text { to fetal phase protocol }\end{array}$} & Self-rating & 19 & 3.86 & 0.72 & \multirow{2}{*}{0.595} \\
\hline & ToT & 19 & 3.82 & 0.71 & \\
\hline \multirow{2}{*}{$\begin{array}{l}\text { Performing the } 11 \text { weeks to } \\
13 \text { weeks }+6 \text { days protocol }\end{array}$} & Self-rating & 19 & 3.98 & 0.73 & \multirow{2}{*}{0.723} \\
\hline & ToT & 19 & 4.07 & 0.57 & \\
\hline \multirow{2}{*}{$\begin{array}{l}\text { Evaluating the uterus and } \\
\text { placenta }\end{array}$} & Self-rating & 19 & 4.05 & 0.65 & \multirow{2}{*}{0.307} \\
\hline & ToT & 19 & 3.85 & 0.58 & \\
\hline \multirow{2}{*}{$\begin{array}{l}\text { Evaluating the head and } \\
\text { face anatomy }\end{array}$} & Self-rating & 19 & 4.50 & 0.75 & \multirow{2}{*}{$0.040^{*}$} \\
\hline & ToT & 19 & 3.92 & 0.69 & \\
\hline \multirow{2}{*}{$\begin{array}{l}\text { Evaluating the chest and } \\
\text { heart anatomy }\end{array}$} & Self-rating & 19 & 4.63 & 0.96 & \multirow{2}{*}{0.506} \\
\hline & ToT & 19 & 4.58 & 0.77 & \\
\hline \multirow{2}{*}{$\begin{array}{l}\text { Evaluating the abdomen } \\
\text { and pelvis anatomy }\end{array}$} & Self-rating & 19 & 3.96 & 0.87 & \multirow{2}{*}{$0.027^{\star}$} \\
\hline & ToT & 19 & 3.61 & 0.62 & \\
\hline \multirow{2}{*}{$\begin{array}{l}\text { Evaluating the anatomy of } \\
\text { the spine and extremities }\end{array}$} & Self-rating & 19 & 4.23 & 0.80 & \multirow{2}{*}{$0.044^{*}$} \\
\hline & ToT & 19 & 3.92 & 0.48 & \\
\hline
\end{tabular}

${ }^{*}$ Statistically significant at $5 \%$ level. 
average household income $\left(\chi^{2}=22.13, P=0.000, d f=4\right)$ and education level $\left(\chi^{2}=30.94, P=0.000, d f=4\right)$ was found. A significant association was also recorded between obstetric ultrasound utilization and marital status $\left(\chi^{2}=7.90, P=\right.$ $0.031, d f=3)$, pregnancy gestation $\left(\chi^{2}=1.69, P=0.008, d f=3\right)$ and distance to the nearest ultrasound screening facility $\left(\chi^{2}=14.17, P=0.003, d f=3\right)$. No association was however recorded between obstetric ultrasound utilization and gravidity.

Housewives were more likely (50.5\%) to undergo obstetric ultrasound screening with the employed women being the least $(17.6 \%)$ group to do the same.

On the average household income, according to the study, the more one earned, the more the likelihood of accessing ultrasound screening. For instance, out 22 respondents who earned $\$$ between $\$ 301-\$ 500,81.8 \%$ of them were able to access ultrasound while all the respondents who earned $\geq \$ 700$ were able to access the service. On education level, out of 13 respondents who had attained university education, only one (7.7\%) did not access ultrasound services compared to $88.2 \%$ of those who had no education. The likelihood of accessing ultrasound services was higher among those living nearer to the health facility compared to those leaving far away from the health facility. For instance, out of the 19 respondents who leaved more than $10 \mathrm{~km}$ from the health facility, 73.7\% had not done ultrasound services.

It was also found that training and continuous hands-on mentorship of midwives contributed a lot to the appropriate basic ultrasonography skills acquisition my midwives which in turn contributed to the level of confidence both clients and TOTs had on them. The competencies rating was done in a scale of 1 to 5 (with 5 representing proficient and 1 representing poor skills) as depicted in Table 5 and Figure 2.

\subsection{Predictors of Ultrasound Utilization}

As summarised in Table 6, a logistic regression was performed to ascertain the effects of age, religion, marital status, highest education level, employment status, average household income, pregnancy gestation, facility type and distance to the nearest ultrasound screen facility on the likelihood that participants utilizing the obstetric ultrasound scan. Of all the 10 variables, only three variables (highest education level, pregnancy gestation and distance to the nearest ultrasound screening facility) were found to significantly predict the likelihood of utilizing the ultrasound services $(P<0.05)$. According to the study, the odds of utilizing ultrasound services was 2.8 times greater for participants with primary education, 4.2 times greater for participants with secondary education and 37.779 times greater for participants with university education as opposed to those with no formal education holding other factors constant. This shows that increase in education level of a respondent was associated with an increased likelihood of utilizing the obstetric ultrasound scan services. 


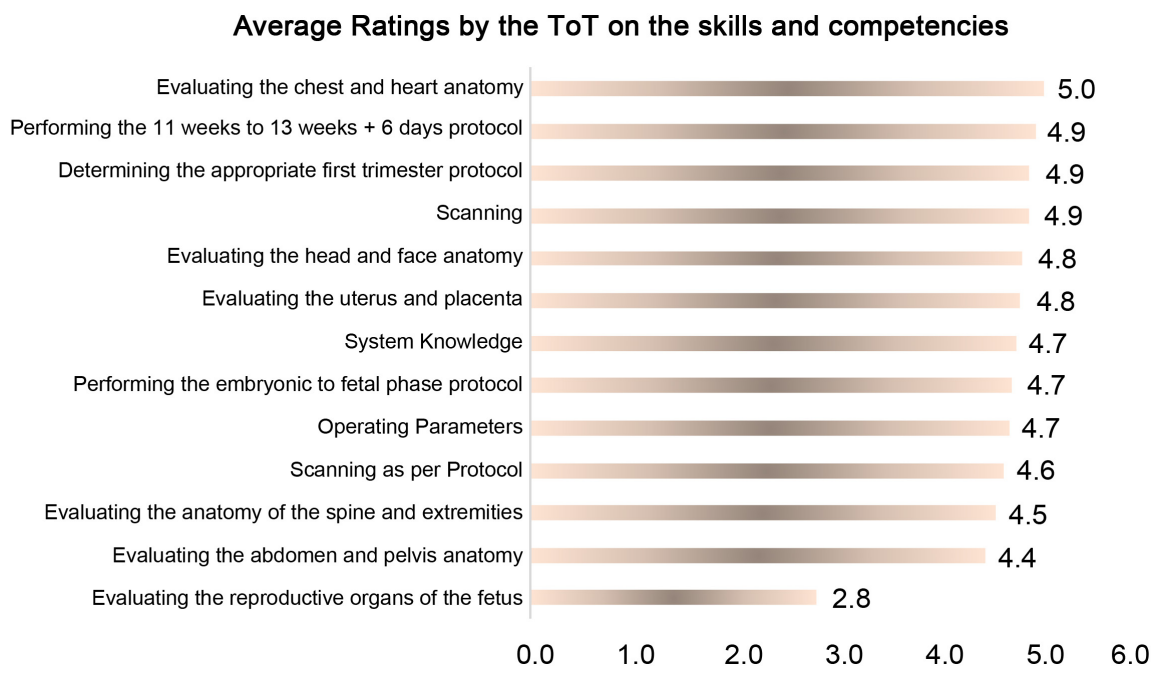

Figure 2. TOTs (sonographers) rating of midwives' basic obstetric ultrasound screening competencies.

In relation to the pregnancy gestation, the odds of utilizing ultrasound services was found to be 4.201 times greater for participants in their second trimester as opposed to those in their first trimester. Similarly, the odds of utilizing ultrasound services was 6.187 times greater for participants in their third trimester as opposed to those in their first trimester.

Distance to the nearest ultrasound screening facility also had a significant effect in predicting the likelihood of utilizing the ultrasound services. For instance, the odds of utilizing ultrasound services was much lower for participants whose nearest ultrasound screening facility was more than 10 kilometres from where they lived as compared to those whose nearest ultrasound screening facility was less than 3 kilometres away.

\section{Discussion}

Ultrasound has become an indispensable part of modern antenatal care (ANC) in both developing and industrialized countries. Ultrasound is safe, portable, less expensive than other imaging modalities, non-invasive, and has a real-time imaging capability that is essential in obstetrics. The recent advances in methods of prenatal diagnosis, particularly prenatal ultrasound have resulted in a better understanding of certain congenital anomalies and consequently, the improvement in surgical and medical procedures to treat birth defects earlier with improved outcomes [12].

It is generally accepted that in majority of developing countries and mostly in rural areas, diagnostic imaging is often insufficient, and in some instances completely lacking. However, over the past decade, the use of clinician-performed, hand-carried, bedside ultrasound has gained increasing popularity as a useful imaging modality worldwide, helping to boost the diagnostic capacity in rural areas in resource-limited settings. Although utilization of ultrasound technology differs across countries, emerging increase in ultrasound services utilisation is 
Table 6. Relationship between ultrasound utilization and other factors.

\begin{tabular}{|c|c|c|c|c|c|c|}
\hline & \multicolumn{6}{|c|}{ Underwent obstetric ultrasound screening during your last/latest pregnancy? } \\
\hline & No & Yes & All cases & $\begin{array}{c}\text { Fisher's } \\
\text { Exact }\end{array}$ & P-value & Cramer's V \\
\hline \multicolumn{7}{|c|}{ Employment Status } \\
\hline Housewife & $109(59.2)$ & $92(50.5)$ & $201(54.9)$ & \multirow{4}{*}{13.638} & \multirow{4}{*}{$0.001^{* *}$} & \multirow{4}{*}{0.191} \\
\hline Self-employed & $65(35.3)$ & $58(31.9)$ & $123(33.6)$ & & & \\
\hline Employed & $10(5.4)$ & $32(17.6)$ & $42(11.5)$ & & & \\
\hline Total & $184(100.0)$ & $182(100.0)$ & $366(100.0)$ & & & \\
\hline \multicolumn{7}{|c|}{ Average household income for the nuclear family per month } \\
\hline$\leq \$ 100$ & $140(76.1)$ & $110(60.4)$ & $250(68.3)$ & \multirow{6}{*}{22.131} & \multirow{6}{*}{$0.000^{* *}$} & \multirow{6}{*}{0.246} \\
\hline$\$ 100-\$ 300$ & $39(21.2)$ & $42(23.1)$ & $81(22.1)$ & & & \\
\hline$\$ 301-\$ 500$ & $4(2.2)$ & $18(9.9)$ & $22(6.0)$ & & & \\
\hline$\$ 501-\$ 700$ & $1(0.5)$ & $7(3.8)$ & $8(2.2)$ & & & \\
\hline$\geq \$ 700$ & $0(0.0)$ & $5(2.7)$ & $5(1.4)$ & & & \\
\hline Total & $184(100.0)$ & $182(100.0)$ & $366(100.0)$ & & & \\
\hline \multicolumn{7}{|c|}{ Education level } \\
\hline None & $15(8.2)$ & $2(1.1)$ & $17(4.6)$ & \multirow{6}{*}{30.943} & \multirow{6}{*}{$0.000^{* * *}$} & \multirow{6}{*}{0.286} \\
\hline Primary & $57(31.0)$ & $38(20.9)$ & $95(26.0)$ & & & \\
\hline Secondary & $89(48.4)$ & $87(47.8)$ & $176(48.1)$ & & & \\
\hline $\begin{array}{l}\text { Mid-level } \\
\text { college }\end{array}$ & $22(12.0)$ & $43(23.6)$ & $65(17.8)$ & & & \\
\hline University & $1(0.5)$ & $12(6.6)$ & $13(3.6)$ & & & \\
\hline Total & $184(100.0)$ & $182(100.0)$ & $366(100.0)$ & & & \\
\hline \multicolumn{7}{|c|}{ Marital Status of the respondent } \\
\hline Married & $143(77.7)$ & $160(87.9)$ & $303(82.8)$ & \multirow{5}{*}{7.903} & \multirow{5}{*}{$0.031^{\star *}$} & \multirow{5}{*}{0.150} \\
\hline Separated & $3(1.6)$ & $3(1.6)$ & $6(1.6)$ & & & \\
\hline Single & $36(19.6)$ & $19(10.4)$ & $55(15.0)$ & & & \\
\hline Others & $2(1.1)$ & $0(0.0)$ & $2(0.5)$ & & & \\
\hline Total & $184(100.0)$ & $182(100.0)$ & $366(100.0)$ & & & \\
\hline \multicolumn{7}{|c|}{ Pregnancy gestation } \\
\hline $\begin{array}{c}\text { First } \\
\text { Trimester }\end{array}$ & $25(13.6)$ & $7(3.8)$ & $32(8.7)$ & 11.686 & $0.008^{* *}$ & 0.177 \\
\hline $\begin{array}{l}\text { Second } \\
\text { Trimester }\end{array}$ & $54(29.3)$ & $53(29.1)$ & $107(29.2)$ & & & \\
\hline $\begin{array}{c}\text { Third } \\
\text { Trimester }\end{array}$ & $45(24.5)$ & $51(28.0)$ & $96(26.2)$ & & & \\
\hline $\begin{array}{c}\text { Already } \\
\text { Delivered }\end{array}$ & $60(32.6)$ & $71(39.0)$ & $131(35.8)$ & & & \\
\hline Total & $184(100.0)$ & $182(100.0)$ & $366(100.0)$ & & & \\
\hline
\end{tabular}




\section{Continued}

\begin{tabular}{|c|c|c|c|c|c|c|}
\hline \multicolumn{7}{|c|}{ Distance to the nearest ultrasound screening facility } \\
\hline$<3 \mathrm{~km}$ & $45(24.5)$ & $75(41.2)$ & $120(32.8)$ & & & \\
\hline $3-5 \mathrm{~km}$ & $92(50.0)$ & $73(40.1)$ & $165(45.1)$ & & & \\
\hline $6-10 \mathrm{~km}$ & $33(17.9)$ & $29(15.9)$ & $62(16.9)$ & 14.174 & $0.003^{* *}$ & 0.197 \\
\hline$>10 \mathrm{~km}$ & $14(7.6)$ & $5(2.7)$ & $19(5.2)$ & & & \\
\hline Total & $184(100.0)$ & $182(100.0)$ & $366(100.0)$ & & & \\
\hline
\end{tabular}

\begin{tabular}{|c|c|c|c|c|c|c|c|}
\hline \multicolumn{8}{|c|}{ Variables in the Equation } \\
\hline & & B & S.E. & Wald & $\mathrm{df}$ & Sig. & $\operatorname{Exp}(B)$ \\
\hline & Age & -0.007 & 0.028 & 0.064 & 1 & 0.801 & 0.993 \\
\hline & Religion & & & 6.163 & 5 & 0.291 & \\
\hline & Muslim & -1.151 & 0.894 & 1.659 & 1 & 0.198 & 0.316 \\
\hline & Roma Catholic & 0.549 & 0.305 & 3.244 & 1 & 0.072 & 1.731 \\
\hline & Adventist & 0.047 & 0.316 & 0.022 & 1 & 0.883 & 1.048 \\
\hline & Traditional religion & -20.900 & $24,581.183$ & 0.000 & 1 & 0.999 & 0.000 \\
\hline & Other & -0.442 & 1.256 & 0.124 & 1 & 0.725 & 0.643 \\
\hline & Marital Status & & & 0.049 & 3 & 0.997 & \\
\hline & Separated & -0.218 & 0.992 & 0.048 & 1 & 0.826 & 0.804 \\
\hline & Single & -0.029 & 1.299 & 0.000 & 1 & 0.982 & 0.972 \\
\hline & Others & -20.232 & $28,363.895$ & 0.000 & 1 & 0.999 & 0.000 \\
\hline & $\begin{array}{l}\text { Highest } \\
\text { education level }\end{array}$ & & & 6.050 & 4 & 0.023 & \\
\hline & Primary & 1.020 & 0.934 & 1.193 & 1 & 0.048 & 2.773 \\
\hline & Secondary & 1.431 & 0.934 & 2.351 & 1 & 0.029 & 4.185 \\
\hline Step $1^{\mathrm{a}}$ & $\begin{array}{l}\text { Mid-level } \\
\text { college }\end{array}$ & 1.718 & 1.004 & 2.930 & 1 & 0.003 & 5.575 \\
\hline & University & 2.826 & 1.474 & 3.676 & 1 & 0.011 & 16.882 \\
\hline & Employment Status & & & 0.996 & 2 & 0.608 & \\
\hline & Self-employed & -0.167 & 0.290 & 0.333 & 1 & 0.564 & 0.846 \\
\hline & Employed & 0.365 & 0.620 & 0.346 & 1 & 0.556 & 1.440 \\
\hline & $\begin{array}{l}\text { Average household } \\
\text { income }\end{array}$ & & & 5.058 & 4 & 0.281 & \\
\hline & Ksh $10,000-$ Ksh 30,000 & 0.209 & 0.339 & 0.382 & 1 & 0.536 & 1.233 \\
\hline & Ksh $30,001-$ Ksh 50,000 & 1.403 & 0.737 & 3.625 & 1 & 0.057 & 4.067 \\
\hline & Ksh 50,001 - Ksh 50,000 & 2.130 & 1.294 & 2.709 & 1 & 0.100 & 8.415 \\
\hline & $\geq$ Ksh 70,000 & 34.491 & $19,333.243$ & 0.000 & 1 & 0.999 & $953,187,672,167,710$ \\
\hline & Pregnancy gestation & & & 10.587 & 3 & 0.014 & \\
\hline & Second Trimester & 1.435 & 0.547 & 6.877 & 1 & 0.009 & 4.201 \\
\hline & Third Trimester & 1.822 & 0.564 & 10.439 & 1 & 0.001 & 6.187 \\
\hline & Already Delivered & 1.574 & 0.553 & 8.086 & 1 & 0.004 & 4.824 \\
\hline
\end{tabular}




\section{Continued}

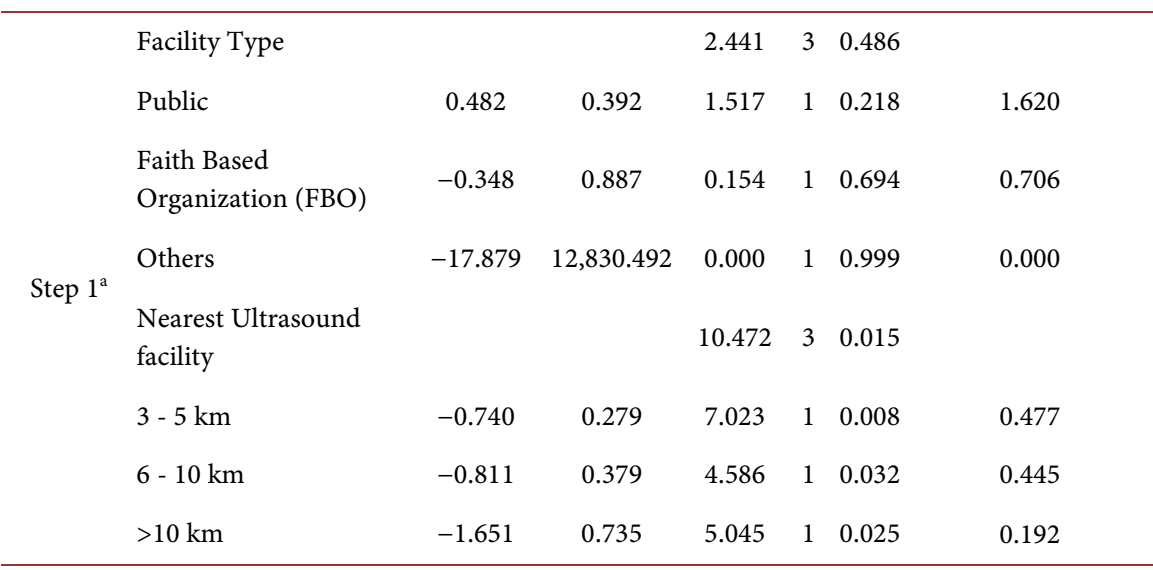

${ }^{a}$ Variable(s) entered on step 1: Age, Religion, Marital status, Highest education level, Employment status, Average household income, pregnancy gestation, facility type, Nearest ultrasound facility.

likely to be due to several factors, including the increased affordability, availability, portability and durability of ultrasound machines [13].

In majority of low middle income countries, ultrasound is mainly used to diagnose obstetric conditions [14]. Unlike in a study in Liberia where $53 \%$ of women utilised related obstetric ultrasound screening service [15], this study recorded approximately half of the respondents had utilised obstetric ultrasound screening services in the selected pilot sites. It is however higher compared to a trial conducted in a refugee camp in Tanzania where only $24 \%$ of the exams were obstetric while $21.9 \%$ were gynaecological [16]. If the above figures are anything to go by, it shows that ultrasound utilization remains low in developing countries. Training of midwives on how to perform basic obstetric ultrasound screening is very critical and valuable enabler; though based in the Nairobi metropolis, findings from a related study at the Agakhan University Hospital [17] established a higher competency rating with an accuracy of $99.63 \%$ among the midwives who had been trained using standardised content. However, in the Agakhan study, images were instantly shared with radiographers via internet to ascertain diagnosis.

A number of barriers to ultrasound services have been documented. In a study carried out in five low and middle income countries, $71 \%$ of patients referred made no attempt to be screened due to high costs involved while $16 \%$ could not afford bus fare to the referral health facilities that had ultrasound machines [18]. Similar to this study, the cost of ultrasound services and distance or transportation difficulties were observed to be common barriers when it comes to utilization of ultrasound services. In our study, the likelihood of utilizing ultrasound services was higher among mothers living near the facility unlike those living far away from health facilities that have POCUS services.

In a qualitative study carried out in Tanzania, all the health workers were in agreement that ultrasound remains a highly valuable tool in management of complicated pregnancy though diverse views were brought up whether routine 
screening ultrasound should be offered to all pregnant women. According to one of the respondent, every woman should have two screening ultrasound examinations, one in the second trimester to determine gestational age and detect fetal anomalies, and another in the third trimester to prepare for any deviations at birth [19]. Similar to the Tanzania study, most of the women who turned for ultrasound screening in this Kenyan study were in their second trimester. Probably this is due to limited awareness among women why they should start ANC visits within the first trimester or as soon as they realise they are pregnant. Unlike in our study where a statistical significance was recorded between utilization and occupation of the respondents, none was found in a study done in Nigeria to determine the factors affecting utilization of obstetric ultrasound services by pregnant women [20].

In a study to determine the maternal perception of barriers to utilization of perinatal ultrasound in the northern part of Nigeria, some of the key factors according to the respondents included necessity of the scan, distance to service point, financial cost, waiting time and satisfaction with service [21]. The findings are similar to our study in which customer care, level of privacy, benefits of ultrasound screening and waiting time were identified as the key influencers to utilization of ultrasound services. In another study carried out among pregnant mothers on how prenatal sonographic services can be improved, good communication between the patient and the sonographer, reducing the cost of scan, reducing the patients' waiting and creating more awareness were some of the opinions shared. In summary, enablers and barriers to utilization of prenatal ultrasound as prenatal care tool are intimately related to, cost, service satisfaction and knowledge of mothers among other factors.

\section{Conclusion}

Prenatal ultrasound covers all aspects of ultrasound imaging tests performed during pregnancy for a variety of reasons. It remains one of the most important advances in antenatal care worldwide given its documented benefits. Key barriers to utilization of this important service include distance to the facilities, inadequate knowledge on the benefits of ultrasound services and the rising cost of these services in the health facilities. From this project, there is evidence that obstetric ultrasound can be cost-effectively decentralized to PHC settings to improve on the quality of antenatal care.

\section{Recommendations}

- Stakeholders need to improve women's knowledge on the benefits of ultrasound screening to improve utilization of obstetric scan.

- National and county governments need to have sustainable financing mechanisms for women to access routine ANC ultrasound services as recommended by WHO.

- Now that ultrasound screening technology is portable, there should be me- 
chanisms instituted by local and national governments to train frontline health care professionals on the same.

- Developing countries to develop clear policy frameworks on how task sharing in the area of obstetric ultrasound screening can be carried out to bridge the gaps of women accessing obstetric ultrasound screening services in developing countries.

- To rapidly accelerate accessibility to the service, Low and Middle Income Countries (LMICs) should have standardized training resources in obstetric ultrasound screening training for frontline health professionals.

\section{Acknowledgements}

We would like to thank our respondents, Kajiado County, Kisii County and the research assistants who made this study a success.

\section{Conflicts of Interest}

The authors declare no conflict of interests.

\section{Funding}

We acknowledge the financial support received from Philips Foundation supported by expertise from Philips. Particularly we acknowledge the programmatic support from Ties Kroezen, June Omollo, Ephantus Mureithi, Christine Apimo and Albert Orwa.

\section{Authors' Contributions}

Matiang'i $\mathrm{M}$ designed, coordinated and oversaw the study, Ngunju P supervised implementation and data collection, Kiilu C digitised and piloted data collection tools while Omogi J drafted the first manuscript while Romy and Marianne contributed a lot of programmatic ideas during project implementation. All authors read and approved the manuscript.

\section{References}

[1] FIGO (2015) Best Practice in Maternal-Fetal Medicine. International Journal of Gynecology and Obstetrics, 128, 80-82. https://doi.org/10.1016/j.ijgo.2014.10.011

[2] WHO (2018) Midwives Are Essential to the Provision of Quality of Care, in All Settings, Globally.

https://www.who.int/news-room/commentaries/detail/midwives-are-essential-to-th e-provision-of-quality-of-care-in-all-settings-globally

[3] Holmlund, S., Ntaganira, J., Edvardsson, K., Lan, P.T., Sengoma, J.P.S., Åhman, A., Small, R. and Mogren, I. (2017) Improved Maternity Care If Midwives Learn to Perform Ultrasound: A Qualitative Study of Rwandan Midwives' Experiences and Views of Obstetric Ultrasound. Global Health Action, 10, Article ID: 1350451. https://doi.org/10.1080/16549716.2017.1350451

[4] Wanyonyi, S., Mariara, C., Vinayak, S. and Stones, W. (2017) Opportunities and Challenges in Realizing Universal Access to Obstetric Ultrasound in Sub-Saharan Africa. Ultrasound International Open, 3, E52-E59. 
https://doi.org/10.1055/s-0043-103948

[5] Downe, S., Finlayson, K., Oladapo, O., Bonet, M. and Gülmezoglu, A.M. (2018) What Matters to Women during Childbirth: A Systematic Qualitative Review. PLoS ONE, 13, e0194906. https://doi.org/10.1371/journal.pone.0194906

[6] Kenya National Bureau of Statistics (2019) 2019 Kenya Population and Housing Census Volume 1: Population by County and Sub-County.

https://www.knbs.or.ke/?wpdmpro=2019-kenya-population-and-housing-census-vo lume-i-population-by-county-and-sub-county

[7] Aziz Ali, S., Ahmed Dero, A., Aziz Ali, S. and Bano Ali, G. (2018) Factors Affecting the Utilization of Antenatal Care among Pregnant Women: A Literature Review. Journal of Pregnancy and Neonatal Medicine, 2, 41-45. https://doi.org/10.35841/neonatal-medicine.2.2.41-45

[8] Kyei-Nimakoh, M., Carolan-Olah, M. and McCann, T.V. (2017) Access Barriers to Obstetric Care at Health Facilities in Sub-Saharan Africa-A Systematic Review. Systematic Reviews, 6, 110. https://doi.org/10.1186/s13643-017-0503-x

[9] Shah, S., Bellows, B.A., Adedipe, A.A., Totten, J.E., Backlund, B.H. and Sajed, D. (2015) Perceived Barriers in the Use of Ultrasound in Developing Countries. Critical Ultrasound Journal, 7, Article No. 11.

https://doi.org/10.1186/s13089-015-0028-2

[10] Andersson, M. (2014) Assessing the Cultural Potential of Ecological Sanitation in Improving Waste Management and Food Security in the Taita Hills, Kenya. Sustainability (Switzerland), 10, 847-854.

[11] Lassi, Z.S., Musavi, N.B., Maliqi, B., Mansoor, N., de Francisco, A., Toure, K. and Bhutta, Z.A. (2016) Systematic Review on Human Resources for Health Interventions to Improve Maternal Health Outcomes: Evidence from Low- and Middle-Income Countries. Human Resources for Health, 14, 10. https://doi.org/10.1186/s12960-016-0106-y

[12] Ikeako, L.C., Ezegwui, H.U. and Onwudiwe, J.E. (2014) Attitude of Expectant Mothers on the Use of Ultrasound in Pregnancy in a Tertiary Institution in South East of Nigeria. Annals of Medical and Health Science Research, 4, 949-953. https://doi.org/10.4103/2141-9248.144923

[13] Sippel, S., Muruganandan, K., Levine, A. and Shah, S. (2011) Review Article: Use of Ultrasound in the Developing World. International Journal of Emergency Medicine, 4, 72. https://doi.org/10.1186/1865-1380-4-72

[14] Stanton, K. and Mwanri, L. (2013) Global Maternal and Child Health Outcomes: The Role of Obstetric Ultrasound in Low Resource Settings. World Journal of Preventive Medicine, 1, 22-29.

[15] Shah, S.P., Epino, H., Bukhman, G., Umulisa, I., Dushimiyimana, J.M.V., Reichman, A. and Noble, V.E. (2009) Impact of the Introduction of Ultrasound Services in a Limited Resource Setting: Rural Rwanda 2008. BMC International Health and $\mathrm{Hu}$ man Rights, 9, Article No. 4. https://doi.org/10.1186/1472-698X-9-4

[16] Blaivas, M., Kuhn, W., Reynolds, B. and Brannam, L. (2005) Change in Differential Diagnosis and Patient Management with the Use of Portable Ultrasound in a Remote Setting. Wilderness \& Environmental Medicine, 16, 38-41.

https://doi.org/10.1580/1080-6032(2005)16[38:CIDDAP]2.0.CO;2

[17] Vinayak, S., Sande, J., Nisenbaum, H. and Nolsøe, C.P. (2017) Training Midwives to Perform Basic Obstetric Point-of-Care Ultrasound in Rural Areas Using a Tablet Platform and Mobile Phone Transmission Technology-A WFUMB COE Project. Ultrasound in Medicine and Biology, 43, 2125-2132. 
https://doi.org/10.1016/j.ultrasmedbio.2017.05.024

[18] Franklin, H.L., Mirza, W., Swanson, D.L., Newman, J.E., Goldenberg, R.L., Muyodi, D., Figueroa, L., Nathan, R.O., Swanson, J.O., Goldsmith, N., Kanaiza, N., Naqvi, F., Pineda, I.S., López-Gomez, W., Hamsumonde, D., Bolamba, V.L., Fogleman, E.V., Saleem, S., Esamai, F., Liechty, E.A., Garces, A.L., Krebs, N.F., Michael Hambidge, K., Chomba, E., Mwenechanya, M., Carlo, W.A., Tshefu, A., Lokangaka, A., Bose, C.L., Koso-Thomas, M., Miodovnik, M. and McClure, E.M. (2018) Factors Influencing Referrals for Ultrasound-Diagnosed Complications during Prenatal Care in Five Low and Middle Income Countries. Reproductive Health, 15, Article No. 204. https://doi.org/10.1186/s12978-018-0647-8

[19] Åhman, A., Kidanto, H.L., Ngarina, M., Edvardsson, K., Small, R. and Mogren, I. (2016) "Essential But Not Always Available When Needed"-An Interview Study of Physicians' Experiences and Views Regarding Use of Obstetric Ultrasound in Tanzania. Global Health Action, 9, Article No. 31062.

https://doi.org/10.3402/gha.v9.31062

[20] Usman, B.O., Idris, S.H. and Umar Abdulaziz, O.A.A. (2020) Factors Affecting Utilization of Obstetric Ultrasound: A Study of Semi-Urban Pregnant Women in a Developing Nation. Sahel Medical Journal, 23, 82-87.

https://doi.org/10.4103/smj.smj_5_19

[21] Ohagwu, C.C., Abu, P.O., Odo, M.C. and Chiegwu, H.U. (2010) Maternal Perception of Barriers to Utilization of Prenatal Ultrasound in Prenatal Care in the Northern Part of Nigeria. Clinics in Mother and Child Health, 7, 1-5. https://doi.org/10.4303/cmch/C101567 